\title{
Slow Down! Digital Deceleration Towards A Socialist Social Media
}

\author{
Jamie Ranger
}

St. Hugh's College, University of Oxford, Oxford, UK, james.ranger@sthughs.ox.ac.uk

\begin{abstract}
Hartmut Rosa argues that three systems of social acceleration (technical acceleration, the acceleration of social change and the acceleration of the pace of life) have emerged as fundamental to the human experience of late modernity. It is here argued that the digital imaginary, specifically curated by the "universal" social media platforms causes what Dominic Pettman has dubbed the "hypermodulation" of the subject, which contributes to the reproduction of the capitalist status quo. Consequently, I here argue that a socialist approach to the digital must commit to what Rosa would term an ideological (oppositional) deceleration to counteract such tendencies.
\end{abstract}

Keywords: digital socialism, social media, acceleration, hypermodulation, deceleration.

Acknowledgement: for Sharon Kits Kimathi; for my parents; for my supervisor Dr. Stuart White.

\section{Introduction}

As Judy Wajcman $(2015,1)$ has noted, "there is a widespread perception that life these days is faster than it used to be". Although there is not unilateral agreement on why, how or to what extent, one would be hard-pressed to find an argument to the contrary. She notes that "talk about life accelerating only makes sense against an implied backdrop of a slower past" (Wajcman 2015, 6), so any account of the acceleration of the pace of life must also provide an account of how we came to be so caught up in such perceived rapidity.

The most comprehensive account of social acceleration, and thus the focus of this paper, is given by Hartmut Rosa, a sociologist writing in the critical theory tradition. He argues that "we cannot adequately understand the nature and character of modernity and the logic of its structural and cultural development unless we add the temporal perspective to our analysis" (Rosa 2003, 4). In his 2013 work Social Acceleration: A New Theory of Modernity, Rosa denotes three systems of social acceleration (technical acceleration, the acceleration of social change, and the acceleration of the pace of life) which have emerged as fundamental to the human experience of late modernity.

Using Rosa's theory of social acceleration, I shall argue that in the context of social media, social acceleration produces conditions which support a capitalist status quo. I shall conclude by constructing an account of 'digital deceleration' as a framework for thinking about socialist policies through the distinctive considerations of both social acceleration and digital politics.

\section{The Features of Social Acceleration}

For Rosa, "acceleration is an irreducible and constitutive trait of modernization" (Rosa 2003,27 ). For modern societies, capitalist economics dictates that productivity and 
growth must be continuously rising just in order to preserve what we already have, and it is this "frenetic standstill" as he refers to it, that leads to a state of individual and institutional inertia, insofar as these rapid changes undermine the belief that our lives and our actions are heading in some meaningful direction. Consider "frenetic standstill" as structurally analogous to the human body undergoing G-force, for example, in a Formula One car or during astronaut training: the acceleration imposed on the body makes movement incredibly difficult, such is the burden of the external gravitational weight, an invisible but dangerously potent relation of force causing both compressive and tensile stress. Rosa wants to explain that the lack of democratic transformation in our state of affairs is partially explained by such a phenomenon, that our institutions feel unable to initiate change because change is continuously enforced from outside, and as such, the uncertainty that is built into the stability of the economic systems of modernity create a sense of retrenchment; taking stock; a conservation of energies.

To return to Rosa's three systems of social acceleration that characterise modernity, technical acceleration refers to the rapid developments in transportation and communication technologies: from horse-drawn carriages to automobiles with engines measured in horsepower, from handwritten letters to direct messaging on social media, from the wireless to the radio to the television to smart television streaming services (Rosa 2013, 97). Technological acceleration is the acceleration that is goal-directed, whether that be in communications, production, or transport. The project of making the Internet faster, of increasing the capacity of mobile batteries, of more powerful engines, of more immediate communications through telephony; all are contributors to the changing perception of time and space in social life. What was once an eight-month trip by sea is now a half-day trip by air: technological progress alongside globalization has compressed space in social life.

The second system of acceleration is the acceleration of social change, related to this first system of technological change, and can be explained anecdotally. When I was in primary school, I was one of the few children who had the privilege of accessing a home computer, where I would sit with my father and he'd watch over my shoulder as I wrote stories in a Word document or played a puzzle game. By being able to turn on the computer and the monitor, click "start", load "Microsoft Word 1995" and type some words onto the screen, I was held up as a computer "whiz" by the teacher and would even be asked to help out with some of the younger children during their ICT lessons. Even if we remove the technological acceleration from this scenario, and the fact that computational power was such that it took half the lesson for the computer to even boot up (!), let us contrast this scenario with my experience working as a teaching assistant in a primary school in 2016: children as young as seven were capable of comfortably navigating protocols for saving their work on a cloud computing system. As for the older children who were at most eleven, never mind playing games. These kids were accessing a coding application that would help them build their own!

These examples give credence to the notion that the rate of technological change has a knock-on effect for social change: certain skill levels or practices are rendered obsolete by the changing relationship between technologies and their users. Looking back with hindsight, my computer skills were woefully overestimated, and if I had pursued a career in computer science rather than political theory because of my supposed mastery of word processing, l'd be sure to have had a rude awakening at some point. Nevertheless, as social change accelerates, the time in which our prior knowledge and experience can be considered to hold value or be applied to under-stand where we might be going is reduced (Rosa 2009, 83). By the time my ex-students grow up to be adults, it may be the case that their coding skills are deemed comparatively primitive, 
as we lean more towards artificial intelligence to support computational processes. It is hard to guess where economic requirements, shifts in our cultural landscape, or technological developments, will require technical prowess. Prior to modernity, the way you boiled water, cooked food, performed daily tasks, would remain the same: you may learn a trade, a skill or a fact about the world in your childhood that would remain true and useful to be taught to your grandchildren. To be modern is to live through technological developments that fundamentally alter the ways in which people interact with their world, to shorten the lifespan of human relationships with particular technologies, and thus give life a sense of fast-paced movement, towards the direction of progress, or otherwise. Progress has its casualties; we are reticent to change, until we have little choice but to change to preserve what we have.

To quote Rosa directly, "social acceleration is defined by an increase in the decayrates of the reliability of experiences and expectations and by a contraction of the timespans definable as the "present'" (Rosa 2010, 16). Modernity has produced a social rapidity, where social beliefs and actions are considered sensible, mainstream, or acceptable, for shorter and shorter periods of time. Rosa refers to these rapid changes in "attitudes and values as well as fashions and lifestyles, social relations and obligations as well as groups, classes, or milieus, social languages as well as forms of practice and habits" (Rosa 2009, 83). Culture moves at a faster pace, where fashion trends, predominant music genres, all the way to political ideologies, are becoming harder and harder to catch up with: keeping "in the loop" is almost laborious, and this analysis is especially prescient in the age of social media, where internet memes and in-jokes can escalate within hours, disappear from relevance within a day and briefly resurface in an ironic, tired or even nostalgic reformulation by the end of a given week ${ }^{1}$.

For Rosa, the third system of social acceleration, the acceleration of the pace of life, can be understood as a form of subjectivity, an effect of feeling as if they are always running out of time, that there are never enough hours in the day; a subjectivity that views time as a commodity to be spent, and to be spent efficiently, a resource becoming scarce. Rosa defines it as "an increase in the number of episodes of action or experience per unit of time, i.e., it is a consequence of trying to do more things in less time" (Rosa 2010, 21). To explain this idea further, Rosa invites the reader to imagine a scenario where you spent two hours a week responding thoughtfully to a stack of a half-dozen letters. With the invention of e-mail, it would only take you an hour to do the same job. But that's not what happens, of course: because you can now transmit your thoughts instantaneously across the world with the click of a mouse, you will sit for those two hours once used for letter-writing and instead try to get through forty or fifty e-mails under your belt, stopping after two hours as even more come flooding in. In other words, we try to compress actions into the time we have, but then this does not

\footnotetext{
${ }^{1}$ We may also wish to incorporate Mark Fisher's (2009) observation, specifically the notion that one of the problems of contemporary culture is the repackaging, collaging and reproduction of older styles for commodification, with little interest in breaking artistic and cultural boundaries and exploring the potential of art in a mainstream context. Fisher, a blogger and music critic as well as a cultural theorist, was particularly damning about the state of the British music scene, commenting in a lecture series that if you turned on any mainstream radio station and listen to the charts, you could be mistaken for thinking that the song could've been written anytime in the last 30/40 years. In other words, the acceleration of cultural change has led to stale imitation and stylistic reproduction, nostalgic homage as a more surefire commercial entity over the risk of authentic expression and experimentation.
} 
give us more free time, rather the feeling of being constantly able to do more, coupled perhaps even with a tinge of guilt about the fact that we have not.

Bart Zantvoort's analysis of Rosa's overarching conceptual paradigm of social acceleration and inertia concludes with the thought that "the frenetic standstill diagnosed by Rosa [...] understood as global cultural-historical or institutional-structural phenomena, cannot be understood separately from the resistances - the vested interests, the ideological investments or the individual compulsions - which cause individuals to maintain the status quo" $(2017,720)$. I echo this sentiment: social acceleration can only be understood, and a political response only articulated, once we can understand the ways in which frenetic standstill is ideologically reproduced. Next, I shall explore Christian Fuchs' Marxist critique of social media; its endemic relationship to capitalism, its logic of profit, and the presentation of the user experience. Then, I shall focus (primarily) on the acceleration of the pace of life as I believe it coherently dovetails with Dominic Pettman's concept of "hypermodulation", from which I shall later argue that democratic socialism ought to concern itself with digital deceleration.

\section{Social Media and Capitalism}

It is argued that one of the key contemporary roles of the digital sociology literature is to acknowledge and address "the entangled nature of the material and the digital, people and machines" (Selwyn 2019, 25). More specifically, it is argued that we live in a "platform" society, where all areas of public and private life are permeated by platforms (van Dijck et al. 2018). Thus, for the theory of social acceleration to plausibly describe our contemporary situation, one would expect some tangible consequence to be found in the digital realm.

Christian Fuchs approaches modern theories of communication, specifically the Internet and social media, from the perspective of critical theory. He argues that social media operates to obscure the pre-existent class conditions of subordination and domination necessarily entailed by the capitalist mode of production (Fuchs 2016, 121). Fuchs discusses what he terms the dialectic of the subject and the object with regards to Internet communications. He argues that human beings, as subjects interacting with the object of social media, use its technologies for creating, sharing and communicating, for collaborative enterprises, and for the fostering of online communities. Through these communicative practices, the world of their social media becomes a "real" world, not only in the physical sense of being stored on computer servers, and accessible through devices, but also in the sense of becoming more concrete and objective on a psychological level.

This online world allows for communities to come to new understandings (and misunderstandings) of the pre-existent social world and produce discourses exclusive to these micro-communities, leading to meaningful interaction possibilities previously unarticulated. As Internet cultures grow, they bleed into the "real" world, as the shorthand and the discursive markers used online become more ubiquitous offline as our expectations change about how often the rest of society uses the internet (Fuchs 2016, 122). For example, the jarring experience one encounters when they overhear a teenager saying "lol" rather than laughing at a joke, blurring the lines between online and offline discourses.

Fuchs argues that the relationship of the individual and the social is "highly antagonistic". Social media can only exist in a context in which people are capable and willing to share, communicate, collaborate and identify with various communities, but that these actions, whilst encouraged on the online sphere by corporate social media, are precisely what the objective social reality has diminished with the individualist culture 
that has emerged in western democracies. Individuals use corporate social media as a means of adhering to the "neoliberal performance principles" as Fuchs calls them, curating a picture of oneself for their social networks, and engaging with others on these platforms through the addition of carefully selected information available for others to view. Social media, in real terms, is a highly isolated and individualistic user experience dressed up as a community experience, and behind the curtain of the selfpresenting "performance", is what Fuchs refers to as the "private property character of social media" (Fuchs 2016, 122). Fuchs develops this idea further:

the fact that user data is sold as a commodity to advertisers- is hidden behind social media"s social appearance: you do not pay for accessing Twitter, Facebook, Google or YouTube. The obtained use-value seems to be the immediate social experience these platforms enable. The commodity character of personal data does not become immediately apparent because there is no exchange of money for use-values that the user experiences (Fuchs 2016, 122).

To posit the idea differently, outside of the language of Marxist economics, social media presents itself as a free-to-use tool for sharing things with your friends. Rather, it is a platform in which you turn yourself into a commodity by feeding advertisers information about your life, values and preferences through acts of curated self-presentation. There exists an ideological injunction to enjoy the social world, to participate not only as a free subject in the rules of the game, but also as an entertained subject, experiencing consumption as a form of ritualistic pleasure; we are all hedonists now. Fuchs argues:

Play labour is the new ideology of capitalism: objectively alienated labour is presented as creativity, freedom and autonomy that is fun for workers. The ideas that workers should have fun and love their objective alienation has become a new ideological strategy of capital and management theory. 'Facebook labour' is an expression of play labour ideology as element of the new spirit of capitalism (Fuchs 2016, 127).

As a consumer, the subject is conventionally presented as free and autonomous, exercising this right to choose by accessing the market economy to purchase commodities at will, within the constraints of one's discretionary income. To reproduce capitalist relations of production, the system must present itself as the best possible system, and corporate media is complicit in maintaining this implicit message to keep the consumersubject represented, and therefore, hegemonic. Social media presents its online platforms are purely for our use and entertainment, even down to their corporate pronouncements of benevolence; Facebook harnesses "the power to share and to make the world more open and connected"; YouTube wants to "connect, inform and inspire others across the globe"; Twitter wants you "to connect with people, express yourself and discover what's happening" (Fuchs 2016, 133).

All major corporate social media present themselves as here to help, as benevolent as the visions of the peer-to-peer Internet of the 1990's, or open-source software made freely available by socially conscious digital incubators: except unlike the utopian dreams of e-democrats, or the tools made available for others such as Wikipedia or Linux, these social media companies are worth billions on the stock exchange, despite their sloganeering implying a higher calling untethered from the demands of the market altogether. 
Fuchs' primary claim is that there is a marked difference between how social media acts and how it wishes to appear to the end user. The purpose of social media is group formation and information exchange, to bring us together. Yet, capitalism subverts these newfound communication possibilities, and "fosters new forms of exploitation, commodification, individualism, and private property" (Fuchs 2016, 138). Whilst social media users upload pictures, message friends and express themselves online, they are funnelling data into a machine that primarily functions to transfer that data footprint into a product for a company to buy, to advertise to you in a way that turns your own sense of self back in on itself, into presenting you with a range of prospective commodity purchases.

Despite these misgivings about the relationship between social media and capitalist exploitation, Fuchs argues that there remains emancipatory potential within the technology: "[it] points towards, and forms together with other technologies, a material foundation of a democratic socialist society, in which the means of physical and informational production are collectively controlled" (Fuchs 2016, 146). The problem is that corporate social media undermines its own political possibilities by serving the capitalist status quo and serves to render new forms of "exploitation and ideology" (Fuchs $2016,146)$. Social media turns consumers into prosumers, individuals compelled to labour for corporate profit under the guise of play; he argues that it is "mistaken to see Facebook as a communications company: it does not sell communication or access to communication, but user data and targeted advert space. Facebook is one of the world's largest advertising agencies" (Fuchs 2016, 170). Although social media platforms provide the capacity for users to communicate, they operate more like an online dating agency, pairing corporate partners with prospective consumers, under the auspice of connecting human beings with each other: except, as the users do not experience this manipulation of their own data, perhaps the analogy is closer to a blind date where you do not know you are being set up.

Fuchs' analysis of social media, specifically the dominant corporate platforms that shape the landscape, calls to mind the assemblage referred to as "The Twittering Machine" by Richard Seymour (2019), a reference to the Paul Klee painting of mechanical birds luring those enchanted by their song into a hidden ravine below. The following section will consider Dominic Pettman's account of social media subjectivity, emboldened with greater plausibility by Fuchs' prior account of social media's economic logic.

\section{Hypermodulation and the Digital Acceleration of the Pace of Life}

Returning to the subject of social acceleration, Judy Wajcman $(2015,5-6)$ notes that "there are both different senses of feeling pressed for time and a range of mechanisms that trigger those feelings". It could be plausibly stated in a digital context that social media, specifically the universal platforms ${ }^{2}$, are predominantly responsible for such

2 The IPPR 2018 Commission for Economic Justice report refers specifically to Facebook, Alphabet, Amazon and Apple as the 'universal platforms' on the grounds "that they have accumulated the most data, developed the most advanced analytical capabilities and gained greatest ownership of the foundational infrastructure, from mapping to cloud computing, that underpins all digital technology" (Lawrence and Laybourn-Langton 2018, 1). In the context of social media, we may refer to Facebook, Twitter and Instagram as the universal social media platforms, given their substantial market share, with the knowledge that Instagram is owned by Facebook and as such, their network effects are pooled, and with the caveat that China has its own internal social media market, which itself has created its own internally dominant platforms. 
affects in contemporary subjectivity. In many ways, the largest platforms arguably resemble states in terms of their internal complexity and their systems of self-governance.

Following on from Christian Fuchs' analysis of the user experience, Dominic Pettman argues that social media represents itself to us as a tailored and unique experience in which the individuality of our identity is paramount, and its form is limitless in the sense that "no two people will navigate the same branching pathways" (Pettman 2016, xi-xii). His approach, which also draws from critical theory, negotiates the modern world of the consumer-citizen, claiming that "we hover between the older conceptions of what it is to be a person- a citizen, with rights, responsibilities, character, agency, identity, and so on- and new, emerging types of being- a consumer, with cravings, likes, profiles, and opinions, leaving a trail of cookie crumbs in our wake" (Pettman 2016, 6). Pettman appeals to the conceptual frameworks of thinkers like Gilles Deleuze and Jean Baudrillard to argue that subjectivity has lost its "scene" and has been replaced by the "ob-scene", by which is meant that traditional distinctions between "public vs. private, self vs. other, subject vs. other" have been eroded and in their place, a subject whose identity is contingent on its consumption, circulation and production of images for a broader technological apparatus. Specifically

the "ecstasy" afforded by social media is decidedly not an overwhelming thrill or sense of bliss, but rather the homeopathic parcelling of tiny and banal moments of recognition, reassurance, ego reinforcement, humblebragging, notoriety, curiosity, shame, and a galaxy of other modest- but collectively significant- affects (Pettman 2016, 10).

Linking this account of social media to Pettman's prior conversation surrounding subjectivity, he makes the compelling claim that social media is not primarily used for enjoyment, so much as to reinforce our identities, and ensure our visibility to our peers. Pettman explores the motivations behind the willingness of users to surrender personal information, photos, videos, conversation logs and other data over to a corporate platform for the validation that network visibility incurs. In this sense, digital natives are "becoming 'exo-subjects', sending selfies out into the void, in the search for validation of a self that is now distributed across the wires" (Pettman 2016, 10). When users are curating their social media presence, they are quite literally ensuring that they are present, that they have the validation of existence in cyberspace, an increasingly important space where the identity is stored permanently, in a way that requires management by the real-world subject; otherwise, one's identity can become shaped by external forces, such as individuals tagging you in unflattering pictures, uploading embarrassing videos, or being criticised on these public platforms without exercising one's right to reply: Fuchs' "play labour" account is almost too optimistic; curating a social media account with the level of detail required to flourish in cyberspace is joyless, uncompensated work, yet it is all but expected of all digital natives.

We can link this scenario to the consequences of social acceleration: because we can express ourselves online, and social media provides a platform to advertise our businesses, support our hobbies, pursue our personal interests, we are slowly inculcated by these heavily addictive technologies to do so with more frequency and intensity than we otherwise would. The fact that we can get instant updates immediately on our phones rather than having to hear about it all on the six o'clock news means that are constantly checking our phones: "it is as though, one day, it's going to bring us the message we have been waiting for" (Seymour 2019, 69). 
Pettman argues that the contemporary subject is being guided by "hypermodulation: the attempt to distract us from the fact that we are indeed being synchronized to an unprecedented degree" (Pettman 2016, 130). The contention is that social media's apparatus distracts its users with small bursts of content that elicit various affective states, often at different times as other users, and at an ever-faster rate. Our emotional states are, therefore, compartmentalized, reduced to quick, sharp reactions to images, reports or actions on an algorithmically determined feed of news unique to the user. He argues that this flattens the user's experience of social reality, which is perceived as a series of unrelated, chaotic micro-events, without a basis to form a coherent overarching social narrative. Social media leaves the subject fragmented and attempting to form a cohesive sense of identification by curating their feed to serve as an echo chamber, or by jumping to unsubstantiated conclusions.

Instead of the conventional understanding of critical theory that we are "alwaysalready" to become a subject, as we operate with an understanding of the signs, symbols and language used for the interpellative process, the fragmentation caused by media representations causes the user to remain "always-nearly" a subject, uncertain of our place in the world: meaning is deferred by the infinite series of distractions. Rather than distraction being used to take our attention away from events that we would otherwise see, Pettman believes that the distraction is the decoy itself: social media is addictive because it distracts us with numerous interpretations, commentaries and reactions to the event that would be conventionally occluded: the political event is distorted through extensive coverage, rather than remaining unknown (Pettman 2016, 11).

The Internet provides users with access to more information, of varying degrees of authenticity and credibility, than ever before in human history, and social media is the most sophisticated attempt (so far) to compartmentalise that information in such a manner as to provide an ongoing report of social experiences, and in doing so, positions the user's auto-curated profile as the location from where to orient this information. Pettman's provocation is that social media protects the status quo by showing you what is happening, but as a series of seemingly unrelated experiential nodes, and at different times as your fellow users, so that you may vent your anger at injustice in isolation, rather than finding a means of protest or resistance in collective outrage. By showing all information and presenting it with the same level of urgency and immediacy, it induces a "flattening" affect for the user: "matters of potentially historic import, like a civil rights issue [...] are now flattened into the same homogeneous, empty digital space as a cute critter or an obnoxious celebrity" (Pettman 2016, 35). By receiving these various interpretations and media representations of numerous events alongside one another from different perspectives, the important political events, and indeed the larger social world, appear chaotic and unintelligible, which discourages active political participation.

However, Pettman's analysis veers towards the conspiratorial in his claim that "it is quite deliberate that while one person is fuming about economic injustice or climate change denial, another is giggling at a cute cat video [...] that nebulous indignation which constitutes the very fuel of true social change can then be redirected safely around the network" (Pettman 2016,29-30, my emphasis). That this controversial claim is made without evidence leaves it dubious but taken as literary license rather than a po-faced accusation, it can be plausibly argued that social media produces this circulation of emotional responses around the network as a coincidental consequence of the platform's structure, in a way that may feel intentional. 
Later, Pettman gives the example of Facebook admitting to "experimenting with users" feeds to ascertain the extent to which they can transfer via "emotional contagion": leading unrelated individuals to experience the same emotional state because of the platform's active intervention and manipulation" (Pettman 2016, 82-84). However, there remains a marked difference between arguing that social media platforms are engaging in a systematic strategy of intentional interpellation and arguing that social media platforms have demonstrated that they are nonetheless capable of doing so. Just because they can, does not mean they are. But given the continuous revelations and scandals breaking about the tech giants, so many that by the time you read this, the one that comes to your mind may be different to the one that I would otherwise propose, would it be particularly surprising if Pettman was right all along?

Returning to the psychological implications for the subject, he argues that the disorientation caused by social media produces "emotional dissonance", because as the user is pulled in different directions that elicit completely incongruous emotional states, "the moral hierarchies of human culture crumble into a caricature of democracy, in which all elements are equal", in which being "charmed by videos of interspecies friendship" and "(almost) simultaneously disgusted by the latest crime footage" (Pettman 2016,37 ) leads to a blurring of events into individual moments that prompt virtual reactions; a like, a love-heart, a share, a retweet.

Social media produces a vision of a world too chaotic to be challenged, where the subject is enticed into fitting into the social machine without friction to "get on" in life, and to move from distraction to distraction. Whilst Pettman envisions a world where social media designers build distraction into the model for nefarious political ends, I here argue there is a more plausible explanation: hypermodulation is not a political conspiracy, but an unintentional consequence of the incentive structure of platform capitalism informed by the social acceleration of the pace of life. In other words, hypermodulation is caused by what may be termed the digital acceleration of the pace of life, and thus digital deceleration, the replacement of the universal platforms with alternatives sensitive to these affective conditions, may provide a corrective.

\section{Thinking Deceleration}

When Rosa talks about deceleration, he considers it as something that occurs in five different ways: firstly, the natural and anthropological speed-limits of biological life; secondly, the oases of deceleration that exist either because they eschew modernity in the case of the Amish population of the United States, avoided modernity in the case of excluded, isolated tribal populations, or deceleration/productive patience is required for their process, such as the production of whiskey; thirdly, deceleration can occur as a dysfunctional by-product of acceleration, as is the case for traffic jams; fourthly, functional (acceleratory) deceleration, for example, when time-pressed corporate managers take time to "decompress" on yoga retreats so that they may return to achieve success in their accelerated careers without burnout, or ideological (oppositional) deceleration, with examples such as the (historical) luddites or (contemporary) "deepecology" anarchist movements; fifth and finally, the structural and cultural inertia that occurs as a consequence of frenetic standstill, supported by the (once-popular) claim in sociology and theory that "there are no new visions and energies available to modern society (hence the most notable absence of "utopian energies")" (Rosa 2010, 38-39).

Digital socialist deceleration, I argue, ought to be considered an ideological (oppositional) deceleration, by way of an acknowledgement of structural and cultural inertia, 
which involves rejecting the supporting sociological claims ${ }^{3}$. Digital socialist deceleration rejects the view that we have rejected the end of history and sees this lack of utopian energies because of a collective poverty, or lack of acknowledgement of, radical political thought (with varying theories as to why). We have learned through Rosa's analysis that there are circumstances where deceleration can be a dysfunctional consequence, such as instances where everyone using a new technology causes that technology to malfunction or slow down (think servers crashing on the release date of a highly-anticipated computer game), and there are even instances where deceleration is intentionally inscribed into a system for the purpose of further acceleration (my cynical example would be firms giving workers the weekend so that they are refreshed to be productive on weekdays). What does a socialist project look like under these supposed conditions of modernity? And what role does "modernity" seem to be playing in Rosa's work when many would suggest that "capitalism" would be a more adequate descriptor?

What is modernity if it is not roughly the point at which capitalism began in the western world? What do we have to gain from ignoring the obvious fact that we feel the need to send off fifty e-mails in one sitting because there are external financial pressures beyond technological progress allowing for excess sociability? We are going faster because we must go faster, because we can go faster, because our bosses say that if we can, we should, and if we do not, we will be fired. Rosa argues that the merits of his theory of social acceleration includes its ability to explain "the transformation of the productive and consumptive regimes of modernity- from early modernity to "classical", Fordist modernity and so on to "late modernity" (Rosa 2010, 54). Rosa says that he does not claim that acceleration is the basis for society, rather a "dynamis, its driving force and its logic or law or change" (Rosa 2010,54). Although I would argue that the profit motive serves as the primary engine of change, these competing explanations do not necessarily come into conflict during this paper's analysis of social media. Nevertheless, it seems plausible that social media's relationship to its platform capitalist modus operandi is the driving force behind the hypermodulation of the subject, and thus deceleration of social media will either be instantiated through an anti-capitalist ideological opposition, or interestingly, a functional acceleratory project; in other words, the growing marketplace for products and services that encourage "digital detox". Capitalism attempts to solve the problem it creates itself: a cynical phenomenon exploited by the "happiness industry" (Davies 2015).

Rosa wonderfully articulates the contradiction at the heart of liberal democratic modernity, an individualist subjectivity that privileges autonomy of action and decisionmaking as paramount to what makes us human, and yet paradoxically diminishes our capacity for such prospective actions and decision-making, obscured by the systems of control that permeate and dominate our social structures. The socialist project argues that the capitalist mode of production obstructs the autonomy promised by liberal

${ }^{3}$ Socialism is here defined as commitment to the following principles: equality, insofar as all should have broadly equal access to the necessary material and social means to live flourishing lives of autonomy and self-directed meaning; a commitment to democracy as the political basis for ensuring all have the capacity to make meaningful contributions to the decision-making processes that will shape the social conditions of their lives (and recourse to correct instances of individual or collective injustices); a positive account of freedom shaped by a belief in self-determination and self-actualisation (which is linked to the notion of equality as means of ensuring autonomy); and solidarity, as G.A. Cohen put it, that people should "care about, and, where necessary and possible, care for, one another, and, too, care that they care about one another" (Cohen 2009, 34-35). 
democracy, and as such, a transition to an alternative material state of affairs in concert with a more radical democratic culture will better serve the political goal of human emancipation.

Rosa observes that "in late-modern politics, it is no longer (if it ever was) the force of the better argument which decides on future politics, but the power of resentments, gut-feelings, suggestive metaphors and images" (Rosa 2010, 56), and it could be argued that this political discourse that Rosa considers a cultural consequence of social acceleration, is increasingly and more commonly articulated and circulated on social media.

\section{On Socialist Acceleration v Socialist Deceleration}

As many readers will be familiar with theories on the contemporary left, it is here where the difference between Rosa's account of acceleration and the accounts of left-accelerationism as a political stance become more explicit. When Nick Srnicek and Alex Williams (2013) refer to "accelerationist" politics, they are referring to the notion that capitalism, and its associated productive and distributive processes, should be accelerated instead of overcome, in order to reach socialist ends. In this sense, acceleration is posited as the harnessing of technological capacities that are limited by the capitalist paradigm, rather than being linked to more general understandings of social and cultural change. By characterising technological acceleration in its contemporary form as distinctively neoliberal, they are ostensibly politicising the very framework used in the sociology literature, and ironically, policies that I term "digital decelerationist" for the purposes of thinking within the framework could well be considered accelerationism in the context in which Srnicek and Williams use the term.

Both Rosa and left-accelerationists agree that capitalism alone is not responsible for our contemporary situation: "left-accelerationism begins with the premise that the deterritorializing force is not capitalism itself, but the transition from feudalism to capitalism was the expression of an emancipatory drive that capitalism's reterritorialising dynamics has systematically (but never wholly) suppressed" (Wolfendale 2019). However, where they separate from each other is in political praxis: where Rosa and others see an unstoppable problem that inevitably unfolds from modern life, Srnicek, Williams and other left-accelerationists see an opportunity: but why? The key difference between the sociology literature and the left-accelerationist position is that the latter do not perceive the process of techno-social acceleration as a continuous path through modernity, but rather characterise our contemporary situation as approaching a crisispoint, a rupture, a disruption: for example, Aaron Bastani (2019) argues that we are approaching the third disruption of capitalism (where the first was the agricultural revolution and the second was the industrial revolution) and that our world must confront the following five crises and its consequence: "climate change, resource scarcity, everlarger surplus populations, ageing and technological unemployment as a result of automation - are set to undermine capitalism's ability to reproduce itself" (Bastani 2019, 48). In other words, whereas Rosa sees a world that may collapse because of its commitment to acceleration, left-accelerationism is more cynical (of capitalism) and less pessimistic (about prospects for the future):

Capitalism has begun to constrain the productive forces of technology, or at least, direct them towards needlessly narrow ends. Patent wars and idea monopolisation are contemporary phenomena that point to both capital's need to move beyond competition, and capital's increasingly retrograde approach to 
technology. The properly accelerative gains of neoliberalism have not led to less work or less stress (Williams and Srnicek 2013).

Left-accelerationists want to push techno-social acceleration further because they perceive capitalism as a limiting, binding agent that is restricting our technological capacities. The existing infrastructure of the global economy ought not to be destroyed, rather harnessed for the purpose of meeting human needs and launching us towards a post-capitalist future. However, given the previously described account of hypermodulation as the subjectivity produced by our contemporary social media systems, I believe that a digital socialist approach must be decelerationist in nature to counteract such tendencies. As shall be demonstrated in the conclusion, the digital decelerationist policies that I conclude by advocating are plausibly compatible with broader left-accelerationist projects in other sectors, although locating compromise between these positions and these different interpretations of "acceleration" as a concept was not an explicit aim of the paper. Given the recent prominent of accelerationism as an in-vogue concept on the both the contemporary left and right, and its specific prominence amongst political circles on the Internet, I believe there is value in distinguishing between Rosa's account of social acceleration and the implications that emerge from his framework, and the way "accelerationism" is interpreted as a process by a distinct, if occasionally overlapping, literature.

\section{Conclusion: Towards A Socialist Digital Deceleration}

In the language that Rosa has given us, therefore, a socialist politics is a politics that wishes to "decelerate" society, insofar as it wishes to undermine the capitalist logic of continuous growth, and undercut the anxious subjectivity driven to action by frenetic standstill. There may be many instances within a broader socialist project where arguments for acceleration hold water (for example, technological progress in renewable energies; Al-driven bureaucracy to support a streamlined and robust welfare state, etc.), but for the limited purposes of this paper, I shall focus on the socialist response to the problem that social acceleration causes for social media, and how best to counteract such tendencies.

If we accept the view that our social media activity provides the illusion of meaningful critical engagement, whilst also reinforcing the hegemonic profitability and ubiquity of the universal platforms, and that hypermodulation induces the kind of passivity, uncertainty and disorientation that Pettman describes, then any attempt to undermine these effects would be a small but substantial contribution to a project of digital deceleration, and thus a rollback of the affective conditions that serve to reproduce the capitalist status quo of contemporary modernity.

On the individual level, Marcus Gilroy-Ware, in his 2017 book Filling The Void: Emotion, Capitalism \& Social Media, concludes by offering suggestions to counteract what Pettman would term hypermodulation, as well as undermine the dominance of these digital institutions. Gilroy-Ware suggests limiting the time spent on the Internet, spent time researching and using independent/ethical/decentralised alternative digital products, limiting the amount of data that you consent to give away, corrupt the data by providing false information to undermine the predictive potential of universal platform algorithms, and resist the urge to care too much about being present and visible on social media (Gilroy-Ware 2017, 188-191). Unfortunately, it's easier said than done, given that the very network effects that encourage one's participation in social media would be lost the moment one turns to more obscure services. In terms of proposals for collective action, he suggests putting public pressure on social media companies 
to change their ways, build your own open technologies and support others in building ethical social media businesses and "reclaim the idea of social media by producing media and culture that use these hallmarks to undermine the artificial, cruel stability of late capitalism and build something better" (Gilroy-Ware 2017, 191).

Digital deceleration, in practice, is a conscious rejection of the valorisation of a productivity-driven, individualist culture, because it is a rejection of the conditions that produce frenetic standstill. Digital deceleration, therefore, would operate as a practical principle of insuring that reforms to digital platforms, networks and data laws would be designed with an overarching commitment to undermine the disorientating experience of digital subjectivity, reducing the hypermodulation of social media users, and building a new relationship between digital consumers and their tools incongruous with the ideological reproduction of capitalist sentiment. Writing with very broad strokes, below are some examples that may correspond to a notion of digital socialist deceleration:

- digital spaces of egalitarian discussion for an indefinite period supported by interaction with an audience (co-operative software model for live streaming as opposed to corporate-owned social media reaction);

- socialist regulation that turns certain apps into non-profits to maximize value, allow for peer-to-peer connection and services to be rendered at lower cost without capitalist extraction (e.g. TFL (Transport for London) needs to produce an Uber app);

- an independent, regulated and verified non-profit Twitter-style social media application in which libel law applies and which is monitored by press regulators (i.e. a slow, factual Twitter that operates as a co-op in which users are paid for both viewing and contributing to the feed);

- an international supreme court composed of technological innovators, IP lawyers (or lawyers that previously worked on the defunct concept of IP, given the scale of our socialist ambitions) and ethicists that can make decisions to limit the scope, scale and application of emergent technologies, to counter the acceleration of exploitative models through rapid corporate investment.

A digital socialist project wishes to advance the cause of democratic socialism, undermine the capitalist relations between human beings when they engage with digital communications, and create conditions for the critical interrogation of ideology on an individual and collective level. A socialist project must acknowledge and respond to the constitutive role that the digital plays in the process of subject formation. A democratic socialist social media, therefore, would be "decelerationist" in this context, by which is meant it would advocate changes in the material life of social media in particular, and the internet in general, that would reduce hypermodulation, caused by the digital acceleration of the pace of life endemic to social media subjectivity. A working principle of digital deceleration is, therefore, merely the idea that any socialist political project oriented towards the digital ought to consider how its prospective interventions (whether they be alternative platforms, legislative agendas or otherwise) serve to influence the subjectivity of its users, and keep in mind the notion that current social media trends in platform design, network effects and content production is skewed towards enabling and augmenting the frenetic standstill of modern capitalist subjectivity. A socialist social media, therefore, must be a decelerated social media.

\section{References}

Bastani, Aaron, 2019. Fully Automated Luxury Communism. London: Verso.

Cohen, Gerald A. 2009. Why Not Socialism? Princeton, NJ: Princeton University Press. 
Davies, William. 2015. The Happiness Industry: How Government and Big Business Sold Us Well-Being. London: Verso.

Fisher, Mark. 2009. Capitalism Realism. London: Zero Books.

Fuchs, Christian. 2016. Critical Theory of Communication: New Readings of Lukács, Adorno, Marcuse, Honneth and Habermas in the Age of the Internet. London: University of Westminster Press.

Gilroy-Ware, Marcus. 2017. Filling the Void: Emotion, Capitalism \& Social Media. London: Repeater Books.

Lawrence, Matthew and Laybourn-Langton, Laurie. 2018. The Digital Commonwealth: From Private Enclosure to Public Benefit. London: Institute for Public Policy Research, Commission for Economic Justice.

Pettman, Dominic. 2016. Infinite Distraction. Cambridge: Polity Press.

Rosa, Hartmut. 2013. Social Acceleration: A New Theory of Modernity. New York: Columbia University Press.

Rosa, Hartmut. 2010. Alienation and Acceleration: Towards a Critical Theory of Late-Modern Temporality. New York: NSU Press.

Rosa, Hartmut. 2009. Social Acceleration: Ethical and Political Consequences of a Desynchronized High-Speed Society. In High-Speed Society: Social Acceleration, Power and Modernity, ed. Hartmut Rosa and William E. Scheuerman, 77-111. University Park, PA: Pennsylvania State University Press.

Rosa, Hartmut. 2003. Social Acceleration: Ethical and Political Consequences of a Desychronised High-Speed Society. Constellations 10 (1): 3-33.

Selywn, Neil. 2019. What is Digital Sociology? Cambridge: Polity Press.

Seymour, Richard. 2019. The Twittering Machine. London: The Indigo Press.

Van Dijck, José, Thomas Poell, and Martijn de Waal, 2018. The Platform Society: Public Values in a Connected World. Cambridge: Polity Press.

Wajcman, Judy. 2015. Pressed For Time: The Acceleration of Life in Digital Capitalism. Chicago: University of Chicago Press.

Williams, Alex and Nick Srnicek. 2013. \#ACCELERATE Manifesto for an Accelerationist Politics. Accessed 10 January 2020. http://criticallegalthinking.com/2013/05/14/acceleratemanifesto-for-an-accelerationist-politics/

Wolfendale, Pete. 2017. "So, Accelerationism, What's All That about?" DEONTOLOGISTICS. deontologistics.wordpress.com/2018/02/18/ofta-so-accelerationism-whats-all-that-about/

Zantvoort, Bart. 2017. Political inertia and social acceleration. Philosophy and Social Criticism 43 (7): 707-723.

\section{About the Author}

\section{Jamie Ranger}

Jamie Ranger is a doctoral candidate at St. Hugh's College, University of Oxford in the Department of Politics \& IR. He works at the intersection of political theory and digital sociology. His DPhil thesis attempts to trace the emergence of "hypersubjectivity", its consequences for political ontology, ideology-critique and radical digital politics, and whether it augments or frustrates the conditions required for a global digital commons. 